\title{
Article \\ Semantic IFC Data Model for Automatic Safety Risk Identification in Deep Excavation Projects
}

\author{
Yongcheng Zhang ${ }^{1, *(\mathbb{D}}$, Xuejiao Xing $^{2}$ and Maxwell Fordjour Antwi-Afari ${ }^{3} \mathbb{D}$ \\ 1 School of Management Engineering, Huaiyin Institute of Technology, Huaian 223003, China \\ 2 Department of Construction Management, Huazhong University of Science and Technology, \\ Wuhan 430074, China; xing021493@163.com \\ 3 Department of Civil Engineering, Aston University, Birmingham B4 7ET, UK; m.antwiafari@aston.ac.uk \\ * Correspondence: cquzhych@hyit.edu.cn
}

check for updates

Citation: Zhang, Y.; Xing, X.; Antwi-Afari, M.F. Semantic IFC Data Model for Automatic Safety Risk Identification in Deep Excavation Projects. Appl. Sci. 2021, 11, 9958. https://doi.org/10.3390/app 11219958

Academic Editor: Diana Kalibatiene

Received: 15 September 2021

Accepted: 22 October 2021

Published: 25 October 2021

Publisher's Note: MDPI stays neutral with regard to jurisdictional claims in published maps and institutional affiliations.

Copyright: (c) 2021 by the authors. Licensee MDPI, Basel, Switzerland. This article is an open access article distributed under the terms and conditions of the Creative Commons Attribution (CC BY) license (https:// creativecommons.org/licenses/by/ $4.0 /)$.

\begin{abstract}
Safety risk identification throughout deep excavation construction is an informationintensive task, involving construction information scattered in project planning documentation and dynamic information obtained from different field sensors. However, inefficient information integration and exchange have been an important obstacle to the development of automatic safety risk identification in actual applications. This research aims to achieve the requirements for information integration and exchange by developing a semantic industry foundation classes (IFC) data model based on a central database of Building Information Modeling (BIM) in dynamic deep excavation process. Construction information required for risk identification in dynamic deep excavation is analyzed. The relationships among construction information are identified based on the semantic IFC data model, involved relationships (i.e., logical relationships and constraints among risk events, risk factors, construction parameters, and construction phases), and BIM elements. Furthermore, an automatic safety risk identification approach is presented based on the semantic data model, and it is tested through a construction risk identification prototype established under the BIM environment. Results illustrate the effectiveness of the BIM-based central database in accelerating automatic safety risk identification by linking BIM elements and required construction information corresponding to the dynamic construction process.
\end{abstract}

Keywords: safety; risk; BIM; IFC schema; deep excavation

\section{Introduction}

Deep excavation construction is a dynamic engineering process with typical features such as time-space and environmental effects, technological complexity, and important variations depending on site conditions. These features result in increased and uncertain safety risks throughout the project life cycle, which makes a project prone to casualties, schedule delays, and cost overruns [1,2]. The safety risk statuses involved in the construction process are changeable because the total life cycle of a deep excavation project is long and affected by various dynamic factors. Thus, performing timely safety risk identification is critical during the preconstruction and construction phases to issue early warnings and adopt preventive measures for the reduction of safety risk events [3].

Traditionally, risk identification is conducted relying on domain expertise and construction experience, along with huge human, material, and time resources [4]. According to risk identification outcomes (e.g., reported potential risk events and factors), risk warnings and correction instructions can be presented to guide later construction activities [5]. In this procedure, construction information, which is scattered in a great amount of interrelated documentation, must be retrieved and extracted manually. Risk identification in the deep excavation construction phase needs consider the construction information in project planning due to the characteristics of temporality, complexity, and dynamics [6]. Presently, safety risk identification and further risk control in both preconstruction and construction 
phases remain imperfect in the project lifecycle, with the implementation process regarded as a "black box" in practice [7].

With the development of information technology in the architecture, engineering, and construction (AEC) industries, building information modeling (BIM) with rich information has facilitated the acceleration of high-quality construction projects [8]. In this context, limited risk identification-related assisting platforms that adopt building information models have been studied [7,9]. Risk reasoning and identification can be supported to promote decision-making by extracting specific construction information from BIM. However, existing platforms are generally limited in terms of information integration and exchange during the automatic safety risk identification of deep excavation in practice. On the one hand, proprietary geometric modeling kernels and data storage formats which constitute the semantic interoperability of these platforms with other software applications can be hampered in practice [10]. On the other hand, inefficient integration of dynamic construction information on sites and risk-related information on information models challenge practical risk identification. Existing research efforts mainly concentrate on data processing and function module design for the development of an assisting platform, with few focusing on information integration and exchange [11]. The Industry Foundation Classes (IFC) standard is a popular neutral and open data exchange format for describing building and construction industry data [12]; thus, it is adopted in this research with the advantage of information sharing and exchange in practice $[9,13]$.

Compared to the traditional way, this research focuses on the method of automatic construction risk identification, aiming at the entire deep excavation process. Information integration and exchange for safety risk identification of deep excavation are explored in this research to address the above research gap by using a BIM-based central database linking the dynamic construction process and risk-related information in project planning. Therefore, this research aims to achieve the requirements for information integration and exchange by developing a semantic industry foundation classes (IFC) data model based on a central database of Building Information Modeling (BIM) in the dynamic deep excavation process. Firstly, safety risks related to deep excavation are analyzed, and construction information required for risk identification is summarized. Then, a semantic data model applied IFC definitions is established, identifying the relationships among required information, involved relationships (i.e., logical relationships and constraints among risk events, risk factors, construction parameters, and construction phases) arising during the dynamic construction process, and BIM elements. The latest version of the IFC standard (i.e., IFC4) is extended to meet the information description requirements. It is hoped that this study can provide a guidance for automatic risk identification in construction management.

\section{Literature Review}

\subsection{Construction Risk Identification-Related Assisting Platforms}

In the AEC industry, various platforms have been studied and applied to support risk identification and management for promoting decision-making. Zhang et al. proposed a BIM platform that can prevent fall-related accidents by reporting safety measures in advance. In this manner, automated hazard identification and safety checking in the construction process can be realized [4]. Ding et al. established an ontology-based methodology for construction risk knowledge management through an information model, taking advantage of semantic web technology [5]. Moreover, a limited number of existing studies have explored the potential of software applications for safety risk identification and control in deep excavation-related fields. Zhou et al. proposed a BIM-based 4D model as an integrated tool to present the real-time visualization safety status of related components under changing conditions [7]. Zhang et al. presented an approach integrating the BIM and the expert system to improve the efficiency of the traditional risk identification process in tunnel construction. The approach enabled knowledge sharing between clients and 
experts [9]. Kiviniemi et al. proposed a 4D information model, integrating safety activities to support the generation of construction planning [14].

The above previous studies prove the potential of assisting platforms (especially, adopting building information models or deep learning-based method) in facilitating automatic risk identification in deep excavation projects [15]. However, these previous studies on assisting platforms are often based on proprietary geometric modeling kernels and data storage formats, which hinder their semantic interoperability with other software applications (e.g., BIM design software) $[10,11]$. Furthermore, when applied to practical risk identification, the integration of construction information on dynamic sites and other risk-related information in different forms remains a challenge. Existing research mainly concentrates on data processing methodologies and the function module design of system applications. Studies focusing on the information integration and exchange of assisting platforms are limited. The development of automatic safety risk identification application in dynamic deep excavation is hampered in practice.

\subsection{Application of IFC to the AEC Industry with Extension}

IFC, as an ISO standard, is a popular, neutral, and open data exchange format for describing construction information [12]. In theory, based on IFC and information delivery standards, different software packages with good IFC interfaces can seamlessly conduct information sharing and exchange. In some construction fields, the latest version of the IFC standard (named IFC4 or IFC2x4) cannot meet information requirements. Thus, the IFC standard should be extended to meet specific project targets to ensure that the required engineering information is captured adequately and completely from certain system applications [16,17]. Based on the engineering characteristics of certain projects, efforts of IFC extension have been implemented in various fields (e.g., bridge $[13,18]$, tunnel $[19,20])$, mainly focusing on construction management [21,22], cost estimation [23,24], seismic components [25], and design change management [26].

Extant review suggests that the IFC data model with extension can be potentially used as a formalized data format to support decision-making in various fields. On the one hand, it can be used to facilitate effective semantic interoperability with other software applications through IFC-based neutral interfaces [11]. On the other hand, the information integration and exchange of practical engineering conditions and IFC-based software applications can be ensured [21]. Thus, IFC is adopted in this research to support automatic safety risk identification and promote decision-making in the deep excavation field, thereby achieving the requirements for information integration and exchange. Based on an IFC data model, this research aims to integrate all risk-related construction information elements and involved relationships (i.e., logical relationships and constraints among risk events, risk factors, construction parameters, and construction phases) that arise during the dynamic construction process. In this procedure, relevant extension work is developed because the current IFC4 standard is limited to meet the above expression requirements.

\section{Research Approach}

Aiming at the automatic risk identification of deep excavation, this research proposes a BIM-based central database, using IFC definitions, to express the risk identification-related information and involved relationships to fill the research gap on information integration and exchange. Furthermore, a safety risk identification approach focusing on the entire deep excavation process is presented. For a systematic and clear process to achieve the above objective, this research adopts the design science research approach, which is a practical multidisciplinary research method applied to various domains [27]. As shown in Figure 1, the process based on the design science research approach incorporates five stages. The motivation of this research is created by reviewing the decision-making for risk identification of the deep excavation process and related assisting platforms (i.e., Stage 1). Then, the research objective is the realization of information integration and exchange for the automatic safety risk identification of the entire deep excavation process 
using a BIM-based central database (i.e., Stage 2). An IFC data model is established by summarizing the information requirements of safety risk identification and completing necessary IFC extension work (i.e., Stage 3). The automatic safety risk identification approach focusing on the entire deep excavation process is presented based on this IFC data model (i.e., Stage 4). Finally, a prototype system for risk identification is designed, and a case study is conducted. In comparison with the manual safety risk identification results, the performance evaluation of the IFC-based safety risk identification is completed (i.e., Stage 5). In the following sections, Stages $3-5$ of the research are explained in detail.

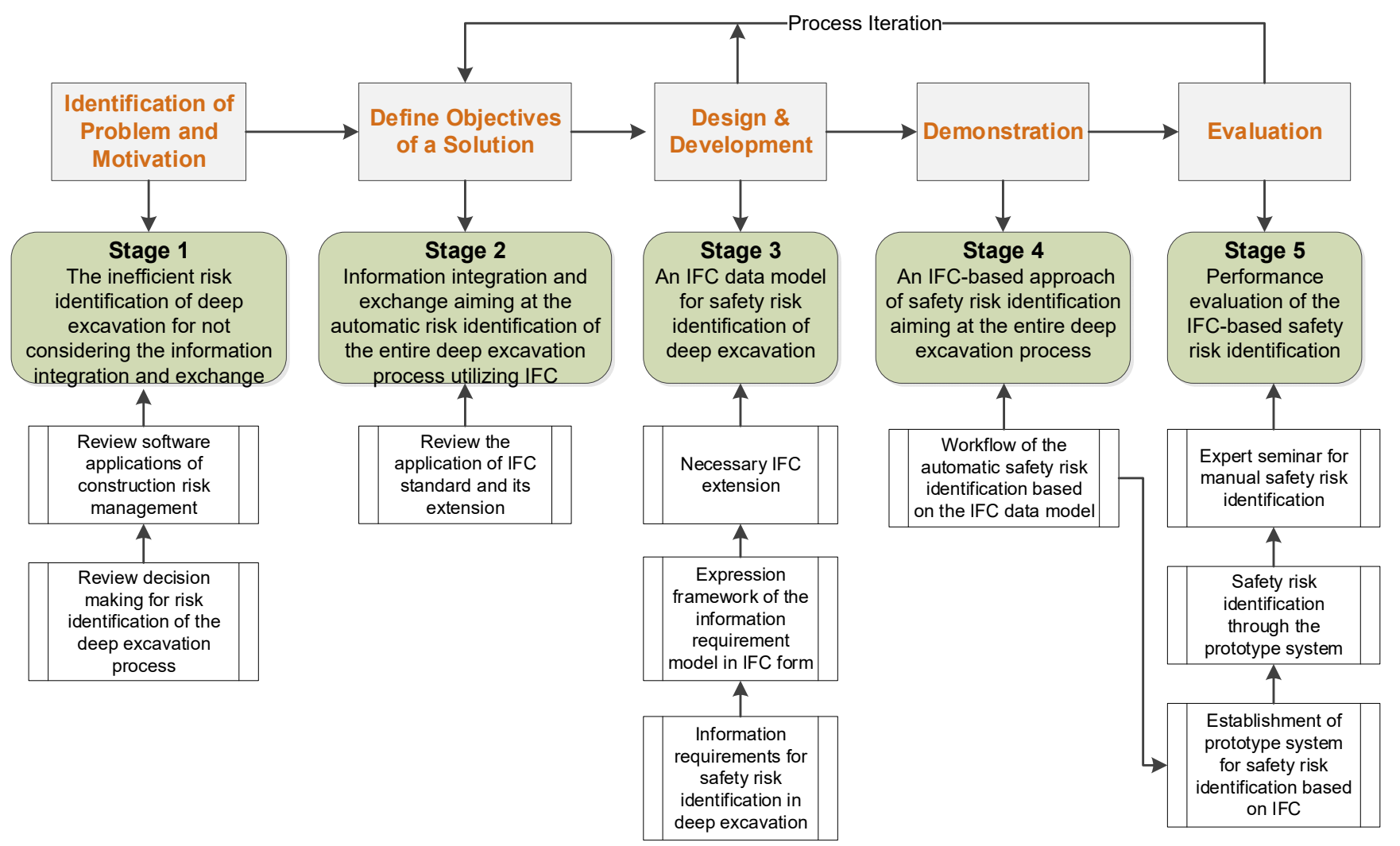

Figure 1. Research process undertaken based on the research approach.

\section{IFC Data Model for Supporting Safety Risk Identification in Deep Excavation 4.1. Information Requirements for Safety Risk Identification in Deep Excavation}

Obtaining the required construction information comprehensively is important to ensure efficient safety risk identification and management. In consideration of the research objective, an information requirement model for safety risk identification (involving information, such as the title of risk events, risk factors, and specific construction parameters contributing to risk factors) should be established first. In this manner, the required construction information corresponding to certain safety risks, which is one of the critical premises of conducting automatic risk identification, can be determined.

As shown in Table 1, in this research, safety risk categories-considered as the safety risk knowledge source-include technical risks, geological risks, and environmental risks $[2,6]$. Other risk categories—such as risks derived from mechanical equipment failure, mishandling, or poor organization, which are indirectly related to construction safety management of deep excavation-are excluded in the first research stage. 
Table 1. Objective risk categories related to construction safety management of deep excavation

\begin{tabular}{ccc}
\hline Risk Category & Description & Examples \\
\hline 1. Technical risk & $\begin{array}{c}\text { Risks caused by project characteristics, such as } \\
\text { adopted construction technologies or methods. }\end{array}$ & $\begin{array}{c}\text { Sand boiling at the bottom of the pit; } \\
\text { Ground heave of the pit bottom. }\end{array}$ \\
\hline 2. Geological risk & $\begin{array}{c}\text { Risks caused by harmful geological or underground } \\
\text { water conditions, such as caves, water capsules, and } \\
\text { poisonous gases. }\end{array}$ & $\begin{array}{c}\text { Leakage of poisonous gas; } \\
\text { 3. Environmental risk }\end{array}$ \\
$\begin{array}{c}\text { Risks related to environmental destruction within } \\
\text { the scope of construction influence, such as damage } \\
\text { to surrounding buildings, structures, and } \\
\text { underground pipelines. }\end{array}$ & $\begin{array}{c}\text { Cracking, slopping, or collapsing of surrounding } \\
\text { buildings (or structures); }\end{array}$ \\
\hline
\end{tabular}

In response to the above safety risk categories, risk identification rules with corresponding risk factors should be established for risk identification. Traditionally, risk identification rules and involved risk factors are often contained in the following three sources $[10,28]$ : (a) empirical knowledge collected from design specifications and construction manuals, (b) theoretical knowledge obtained from statistical models in research papers, and (c) implicit knowledge of domain experts. The risk factors involved in the risk identification rules are often contributed by specific construction parameters corresponding to different construction states. Thus, in this research, the identified risk factors are described by different construction parameters. The following three steps are applied in accordance with previous studies to obtain a detailed list of risk identification rules with specific risk factors $[28,29]$. In practice, the first two steps are applicable to risk events with clear definitions and mechanisms, and the third step can be used on those with uncertainties.

- Step 1: Safety risk events are defined by reviewing the construction documents, through which related engineering terms can also be determined.

- Step 2: Based on the reliability analysis theory, limit state functions can be established to analyze the safety risk events that can be solved with analytic models or by parsing empirical formulas. Risk factors can then be obtained from the independent variables of the limit state functions. For safety risk events where the analytical models are inapplicable, simulation models can be established using appropriate numerical methods, such that the risk factors can be obtained from the parameters of the models.

- Step 3: Additional engineering expertise and practices are required to identify uncertain risk factors.

- An information requirement model aiming at safety risk identification in deep excavation is established (Figure 2).

As shown in Figure 2, the safety risk "Collapse of the retaining system" is presented as an example to illustrate the modeling principles of this information requirement model:

1. This model consists of three layers: risk event, risk factor, and construction parameter. Different factor combinations can result in different safety risk events. Each risk factor is contributed by multi construction parameters.

2. The safety risk events considered in this model are stepwise reclassified based on the adopted construction methods, supporting systems, the three objective risk categories listed above (i.e., technical, geological, and environmental risks), and a risk list of a specific risk category.

3. This research classifies the risk factors into two types: (a) static influential factors, which refer to construction information that can be obtained directly from design documentation before the construction operation stage (i.e., construction design, hydrogeological, and circumjacent environment factors); and (b) dynamic influential factors, which refer to construction information that can be obtained by monitoring concrete construction activities during the construction operation stage (i.e., human behavior, mechanical equipment, and working environment factors). 
4. Automatic risk identification is realized by defining construction parameters as various discontinuous value ranges, which correspond to different certainty factors during the risk reasoning stage. Some construction parameters are defined as 'Yes' or 'No'.

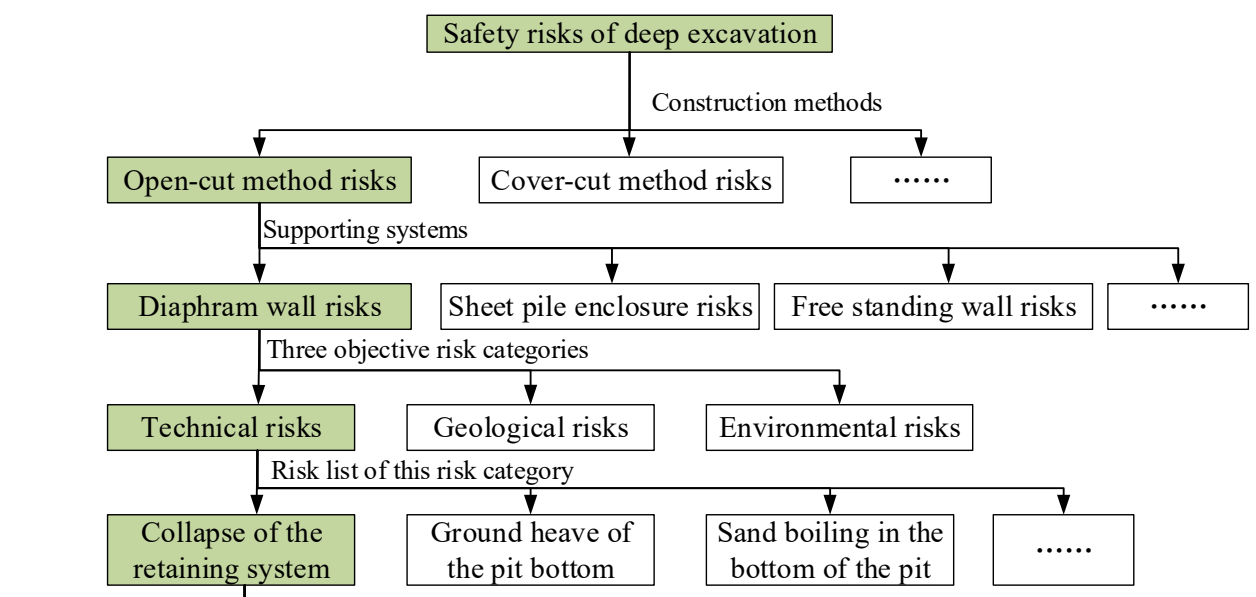

- Static factors $--1--------------\urcorner-----------------$ Dynamic factors -

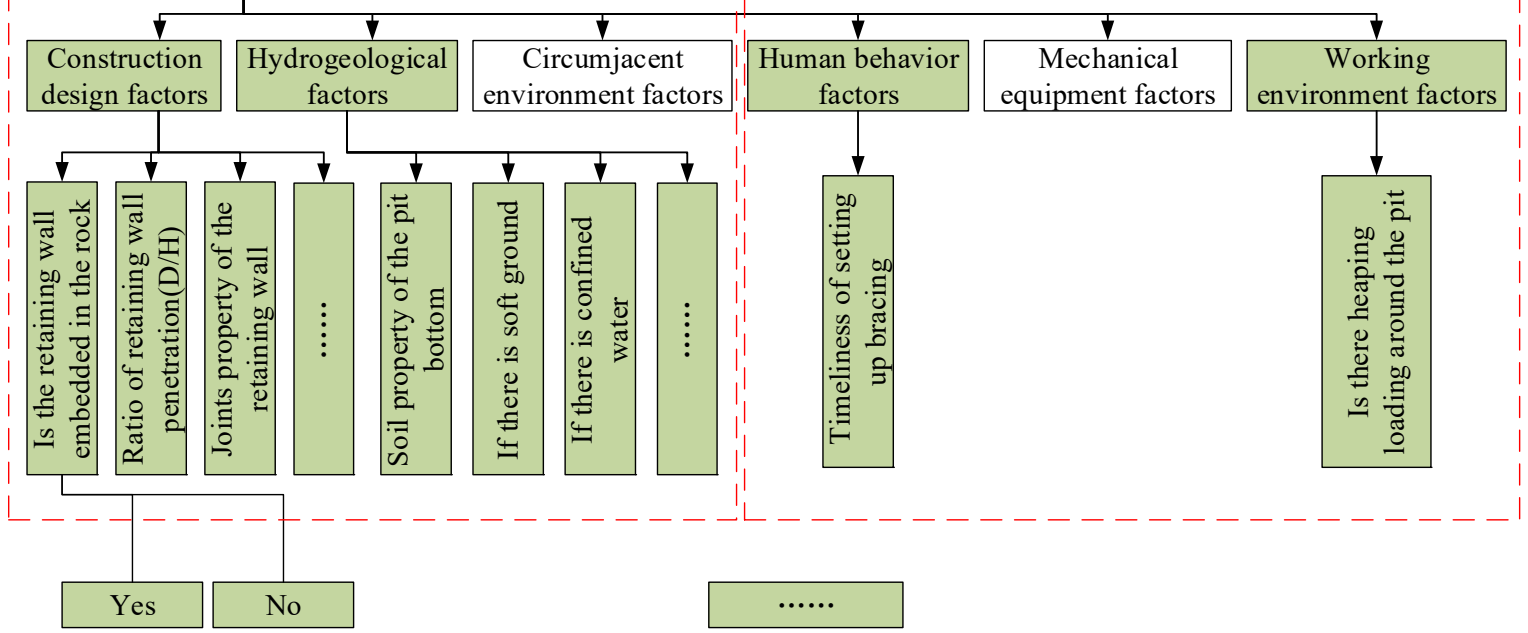

Figure 2. Information requirement model for safety risk identification in deep excavation.

\subsection{Expression Framework of the Information Requirement Model in IFC Form}

Corresponding construction parameters must be extracted from different information elements in the IFC files to identify the risk factors of related safety risks for risk reasoning. Based on the expression methods of IFC4 for describing construction information, an IFC expression framework, which meets the information requirement model, should be designed. In this research, the IFC expression framework consists of four information elements (design, construction, environment, and derived), which correspond to construction parameters reflecting six specific risk factors (Table 2). For simplicity, each information element and its subtypes are assigned with a unique mark in the brackets.

The IFC expression framework of risk information for safety risk identification is shown in Figure 3. The corresponding construction parameters must be extracted from different information elements of IFC files to identify the risk factors of related safety risks for risk reasoning. The following subsection illustrates the expression rules of four information elements in IFC form. Especially, the current IFC4 cannot meet the above 
requirements of information description of the deep excavation field. Hence, extending the IFC4 to guarantee the integrity of the required information of the IFC files is recommended.

Table 2. Four information elements involved in the IFC expression framework

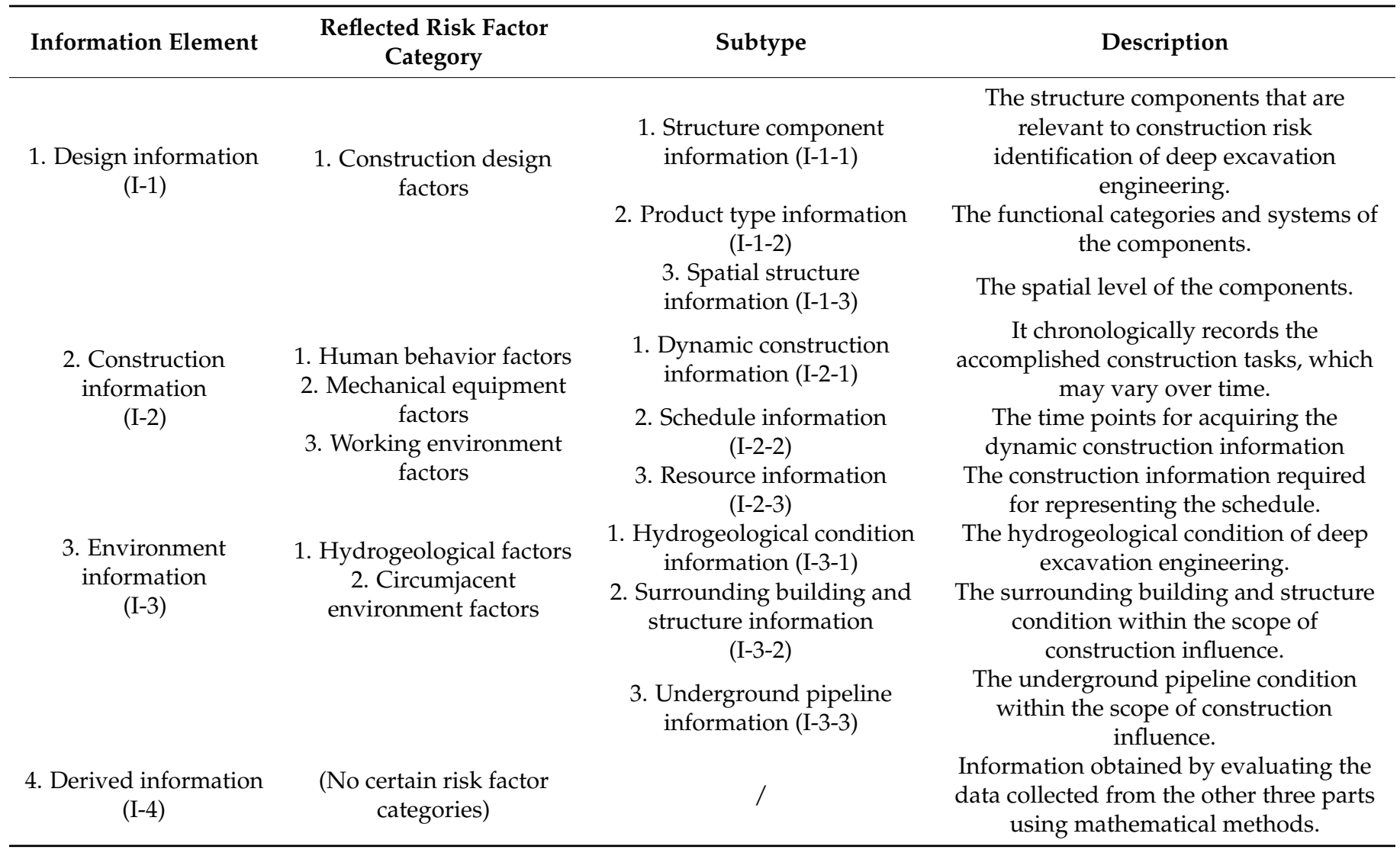

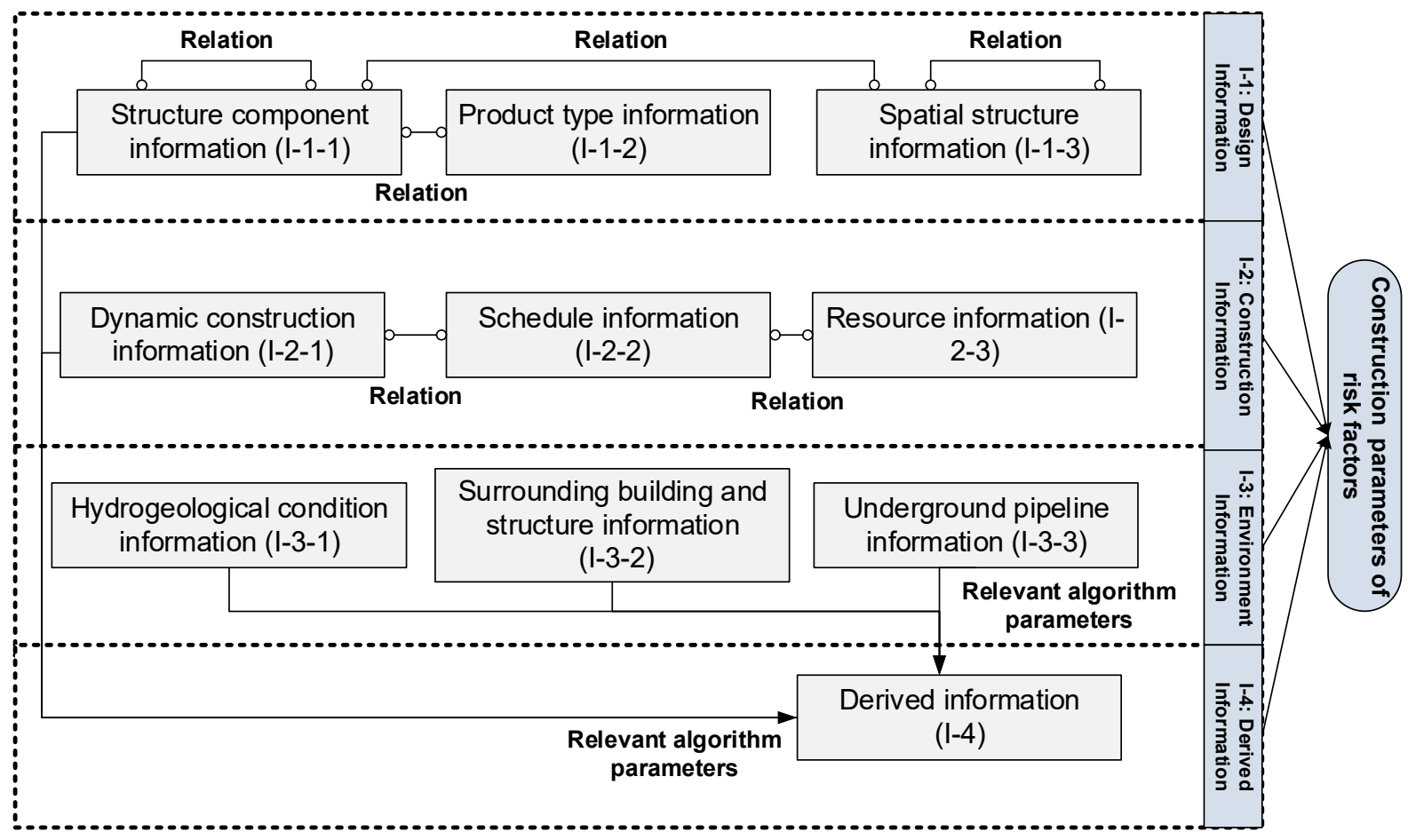

Figure 3. IFC expression framework of risk information for safety risk identification. 


\subsection{IFC Expression of Four Information Elements with Necessary Extension}

\subsubsection{IFC Expression of the Design Information (I-1)}

Figure 4 shows the main structural components in deep excavation, which are classified into different categories and systems (e.g., enclosure, wai purlin, and machinery parts, support (the temporary structure), dewatering, and monitoring systems) according to their typical engineering characteristics. In the following context, the enclosure, the wai purlin, and the supporting system are emphasized to show the IFC expression of the design information (I-1), focusing on its primary and secondary components.

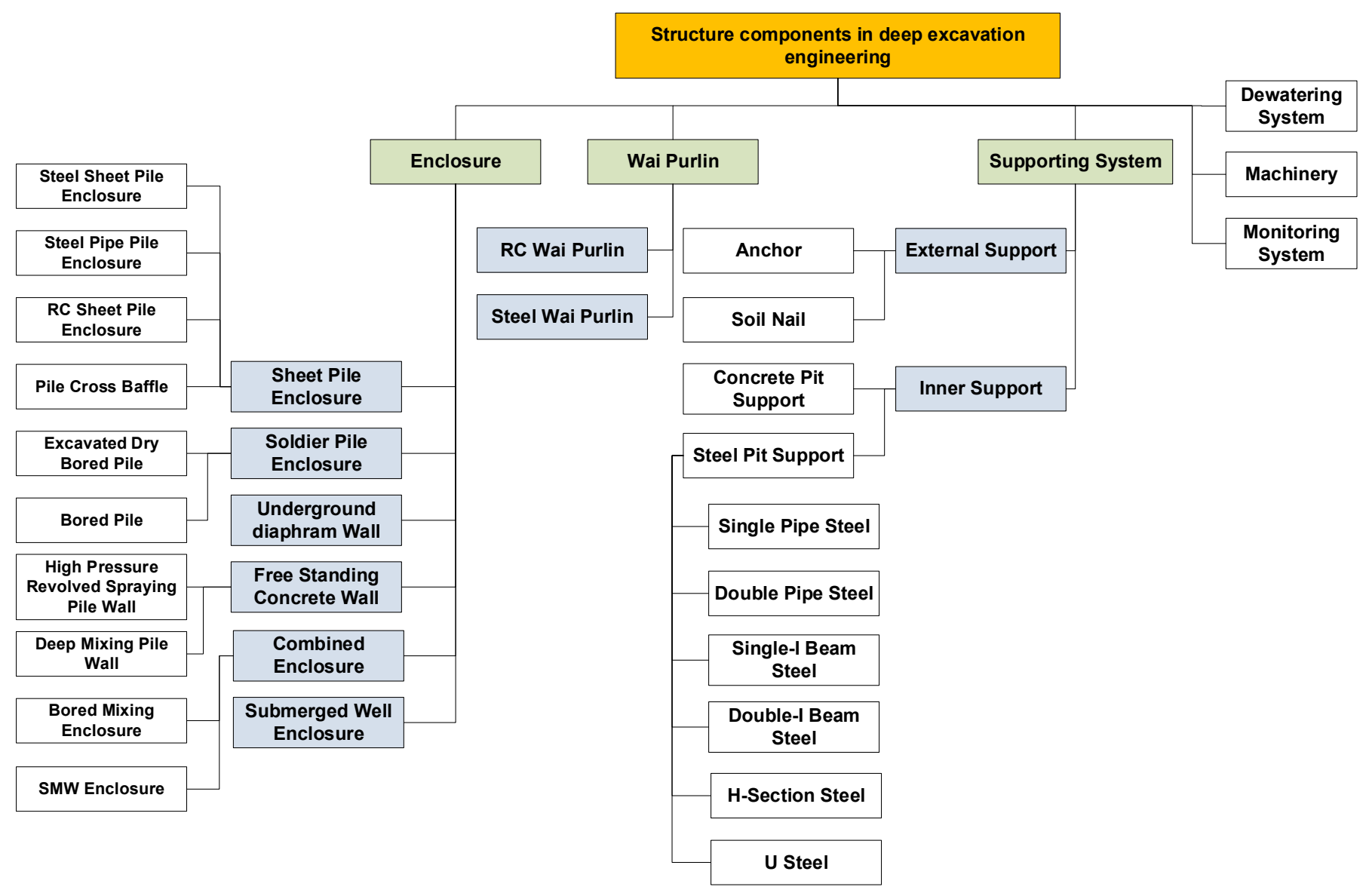

Figure 4. Main structure components in deep excavation.

1. IFC expression of the structure component information (I-1-1)

According to IFC standard, attributes of each object entity and assigned values are expressed through a specific property set. Extension based on property set is used to describe the primary components in deep excavation. Primary components can be described by entities defined in the architecture domain of IFC4 to ensure the compatibility and interoperability of the extended IFC model [30]. New property sets involving construction parameters for safety risk identification are incorporated into these objects as an extension. In this research, for example, the geometric representations of IfcBeam, IfcColumn, IfcPile, and IfcWall described in IFC4 are respectively adopted to present the primary components of the inner support and purlin, the column and diagonal bracing, the pile and waterproof curtain, and the underground continuous wall in deep excavation. Moreover, extended property sets (i.e., Pset_SoldierPile (describing the pile and waterproof curtain), Pset_DiaphramWall (describing the underground continuous wall), and Pset_InnerSupport (describing the inner support)) are created based on practical component characteristics. 
Figure 5 shows the extension of the pile entity (IfcPile) as an example. Relationship entities, such as IfcRelDefinedByProperties or IfcRelDefinedByType can be utilized to establish the relationships between IfcPile and its associated property sets (including the existing sets and the extended Pset_SoldierPile). In correspondence with construction parameters related to risk factors, the properties contained in the extended property set Pset_SoldierPile are shown in Table 3.

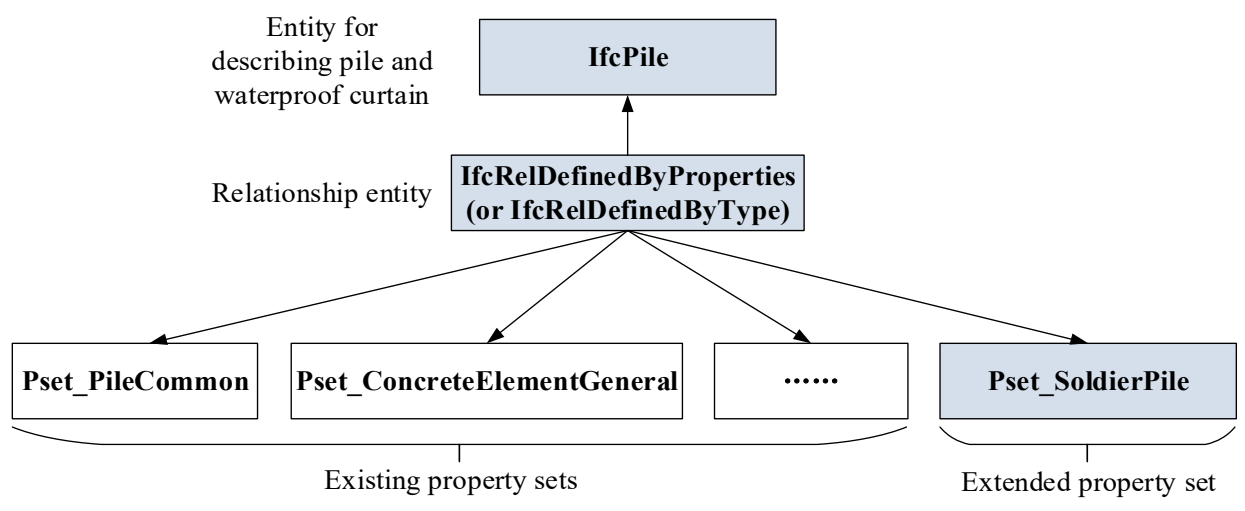

Figure 5. IfcPile with increasing property set.

Table 3. Property set extension of IfcPile

\begin{tabular}{cccc}
\hline Entity & Property Set & Contained Properties & Data Type \\
\hline & & Entering-rock condition & IfcBoolean \\
& & Depth ratio & IfcReal \\
IfcPile & Pset_SoldierPile & Occlusion condition & IfcBoolean \\
& & Diameter & IfcReal \\
& & Water-sealing measure & IfcBoolean \\
\hline
\end{tabular}

Secondary components can be expressed by instantiating the IfcProxy entity objects for good compatibility and ease of operation. For example, in deep excavation, soil nails and anchor bolts can be expressed using user-defined model interfaces provided by the IFC [31].

2. IFC expression of the product type information (I-1-2)

Product type information (I-1-2) can be expressed as shown in Figure 6, with corresponding product type entities extended. These extended entities can be related to structure components using relationship entity IfcRelDefinesByType.

3. IFC expression of the spatial structure information (I-1-3)

The IFC4 standard divides the space of building engineering into four spatial levels (i.e., IfcSite, IfcBuilding, IfcBuildingStorey, and IfcSpace) from the top down. Considering the above space division method and the special engineering characteristics of deep excavation projects, this study divides the deep excavation space into three levels: IfcSite, IfcExcavationPartitionZone, and IfcSupportingLayer (Figure 7). 


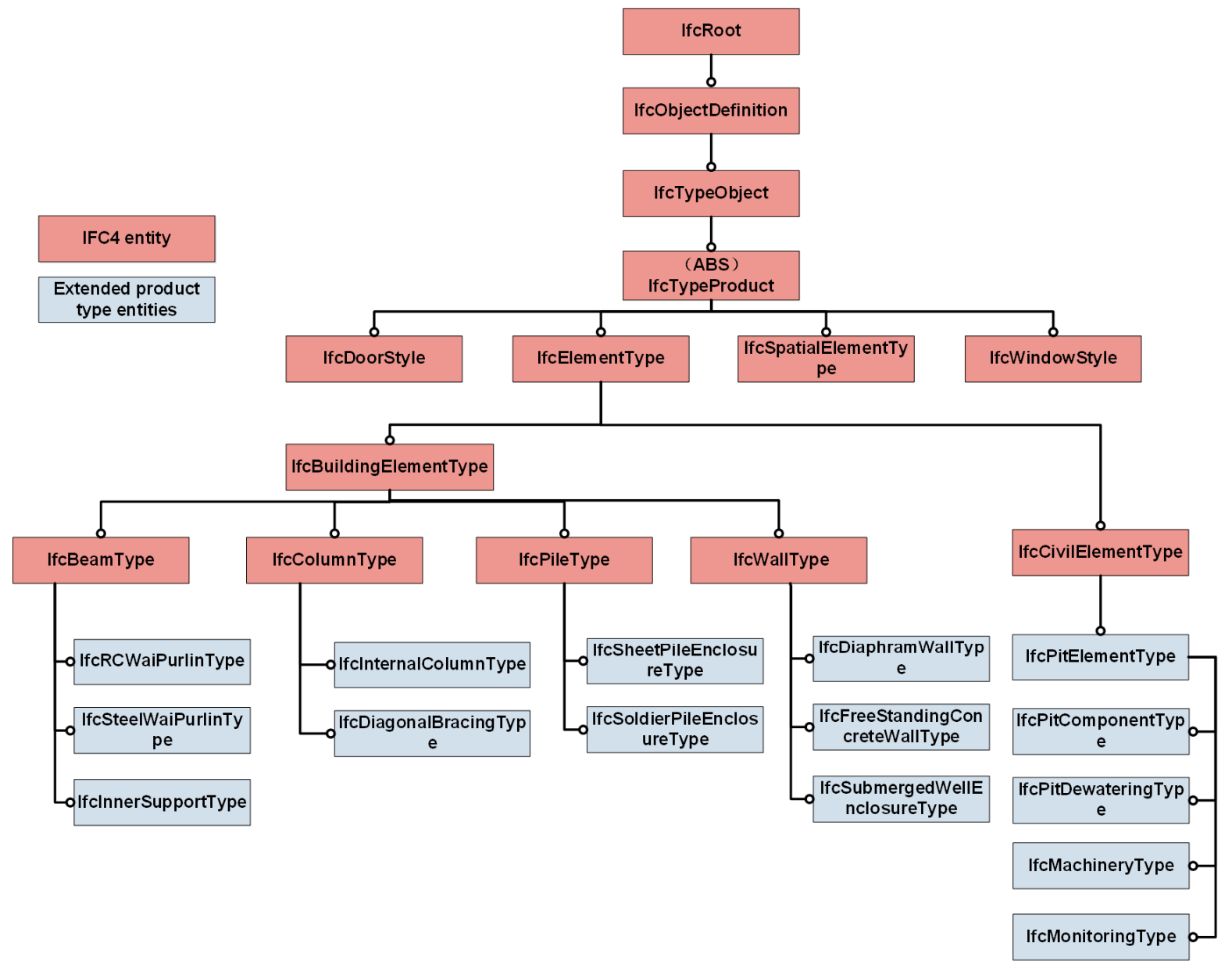

Figure 6. IFC expression with extensions for product type information (I-1-2).

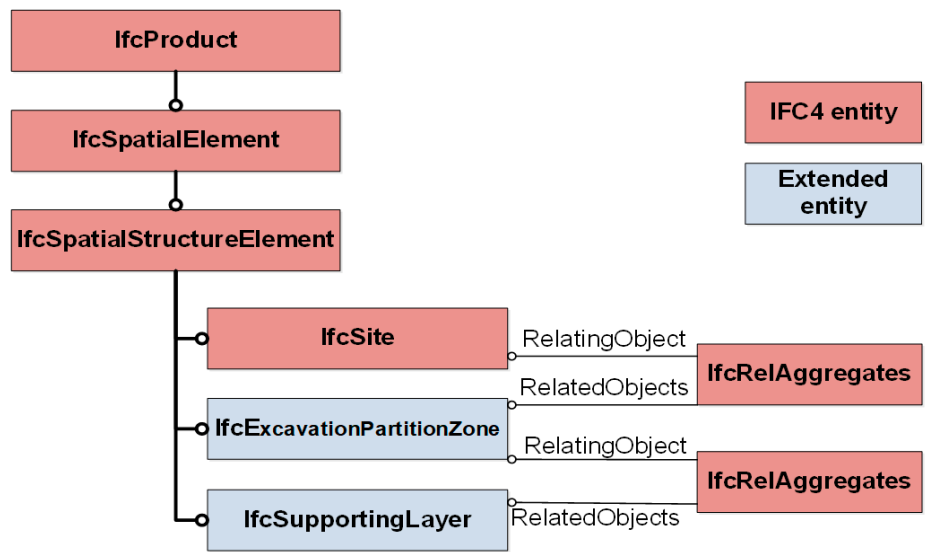

Figure 7. Spatial levels in deep excavation and relationships between spatial entity objects.

4. Relationship expression between structure components

When creating an IFC model for the construction risk identification of deep excavation projects, the actual construction conditions (i.e., construction methods, supporting principles, engineering characteristics, and working conditions) should be considered and addressed. In this manner, the model can express the entity relationships between different physical components reasonably. For example, in deep excavation projects, crown beams are used to maintain the integrity of the supporting system. The crown beams and concrete support are constructed during the same stage. Thus, the crown beams are associated with the reinforced concrete support using the IfcRelConnectsElements entity. 
5. Relationship expression between structural components and their spatial levels

In IFC4, any entity can only be assigned to a certain level of spatial structure to ensure that the relationships between them are explicit. Their connections are established using IfcRelContainedInSpatialStructure. Figure 8 illustrates some essential relationships in deep excavation engineering.

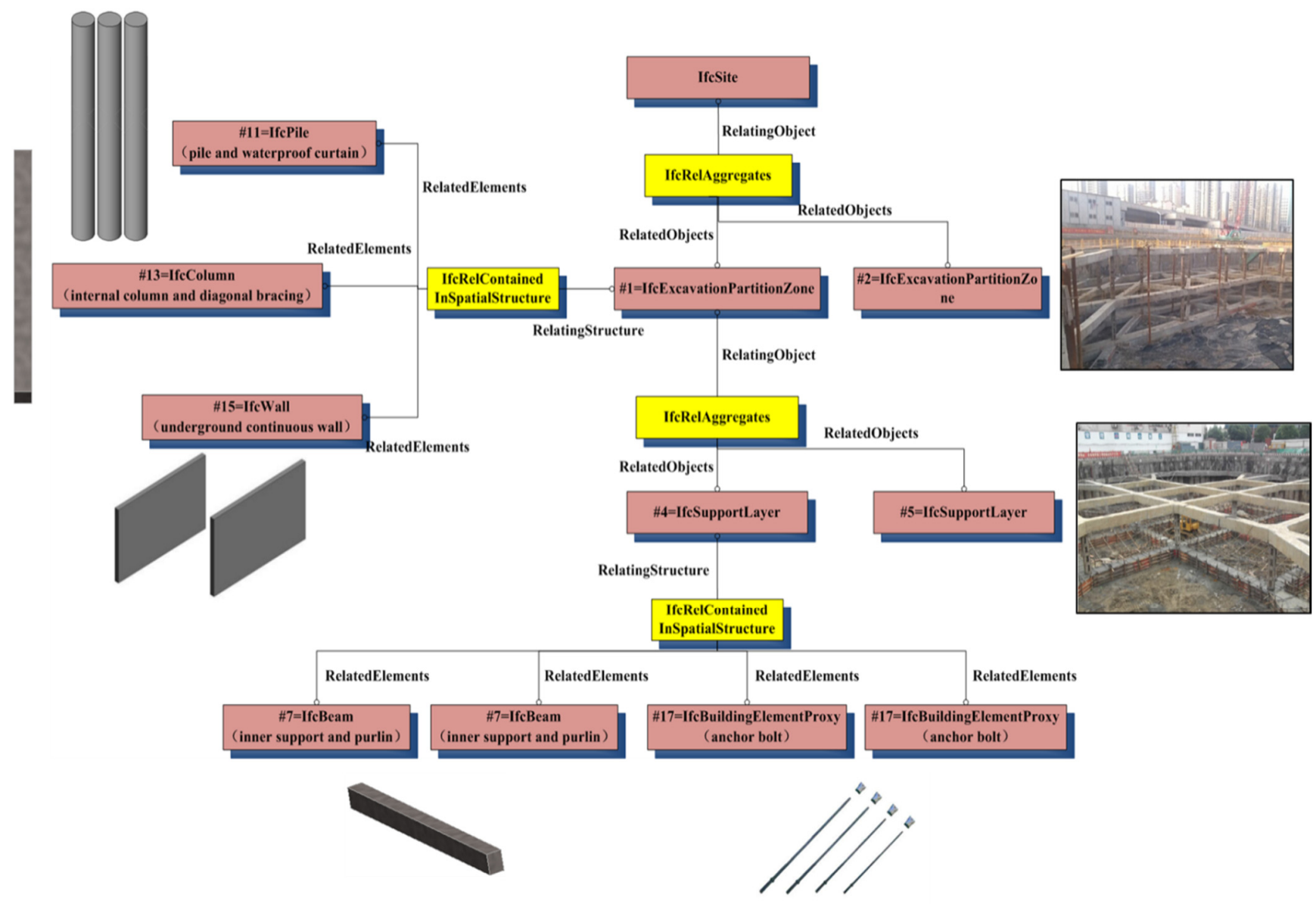

Figure 8. Relationships between spatial and structure component entities in deep excavation engineering.

\subsubsection{IFC Expression of the Construction Information (I-2)}

The construction phase of a deep excavation project is often a long-term and complex process, which consists of various tasks to be completed by multi- and subcontractors. In this phase, various construction information can be involved, such as quantity, schedule, resource, cost, site layout, safety management, and quality evaluation [32,33]. IFC description studies on this construction information can be found in the literature $[23,24,34,35]$. Considering the purpose of realizing automatic safety risk identification of the entire deep excavation, this study mainly focuses on the schedule, resource, and quality evaluation of the construction process, which are construction information related to safety risk factors.

The IFC expression of construction information (I-2) is briefly described in Figure 9. Dynamic construction information (I-2-1) refers to information that may change as the construction stage varies (e.g., the quality evaluation of concrete pouring) [32]. Schedule information (I-2-2) represents the relevant time information in I-2-1, which is expressed using the IfcWorkSchedule entity. Resource information (I-2-3) is expressed using the IfcResource entity. 


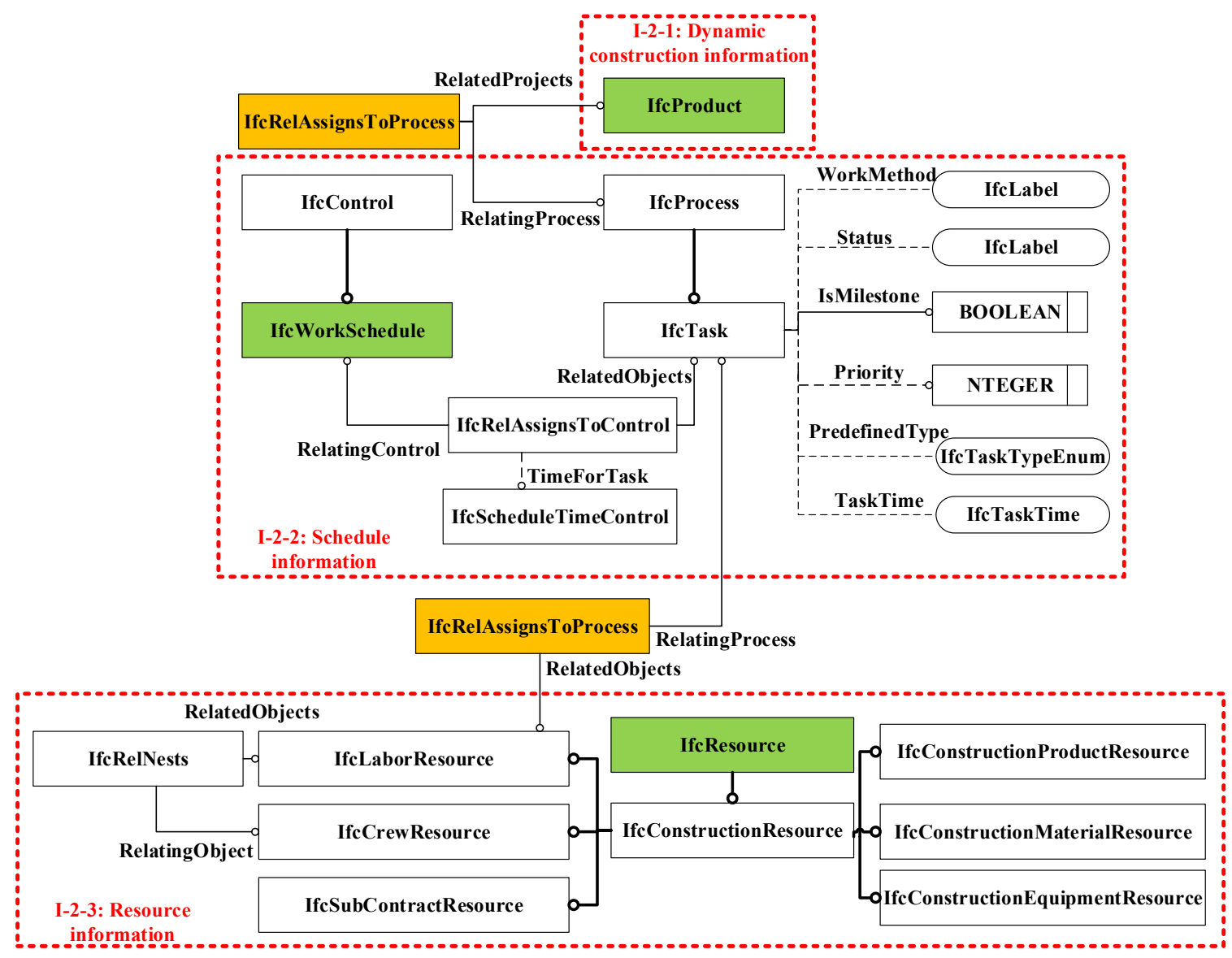

Figure 9. IFC expression of the construction information (I-2).

4.3.3. IFC Expression of the Environment Information (I-3)

IfcGeographicElement is a new entity in IFC4. It represents the features of typical geographical elements within a landscape [31]. In this research, environment information (I-3) is expressed using IFC extension based on entity type, introducing new subclass IFC entities with relevant properties (Figure 10).

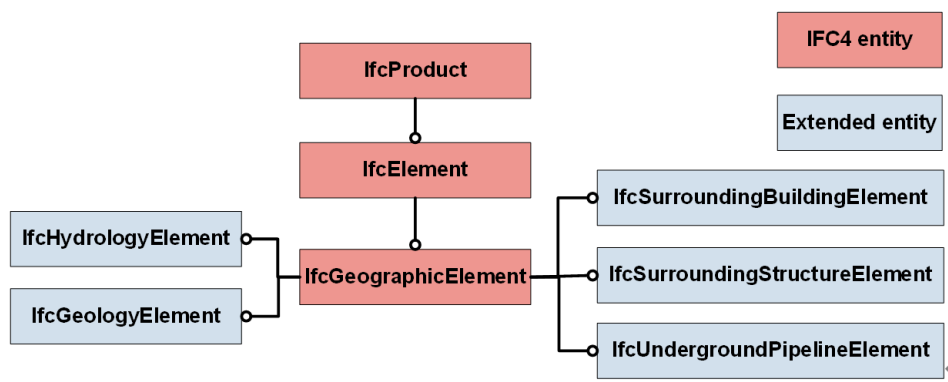

Figure 10. IFC expression of the environment information (I-3).

\subsubsection{IFC Expression of the Derived Information (I-4)}

Some parameters cannot be obtained directly from the object entities, but calculations based on other information parts can be performed. For example, cover-span ratio is obtained via equation $\mathrm{H} / \mathrm{D}$ ( $\mathrm{H}$ is the covering soil depth, and $\mathrm{D}$ is the tunnel diameter). The calculation process is performed during the late risk identification stage through the safety risk identification platform using corresponding mathematical models; thus, the derived information (I-4) is ignored in the IFC model. 


\subsection{Information Integration Using the IFC Data Model}

Based on the IFC expression of different construction information illustrated above, an IFC data model has been established to integrate these information elements for the safety risk identification of deep excavation (Figure 11). Some relationship entities and inheritance relationships are used to relate different information elements. For example, I-2-2 and I-2-3 are linked using IfcRelAssignsToProcess, I-1-1 and I-2-2 are connected using IfcRelAssignsToProcess, and I-1-1 and I-1-3 are associated through IfcRelContainedInSpatialStructure.

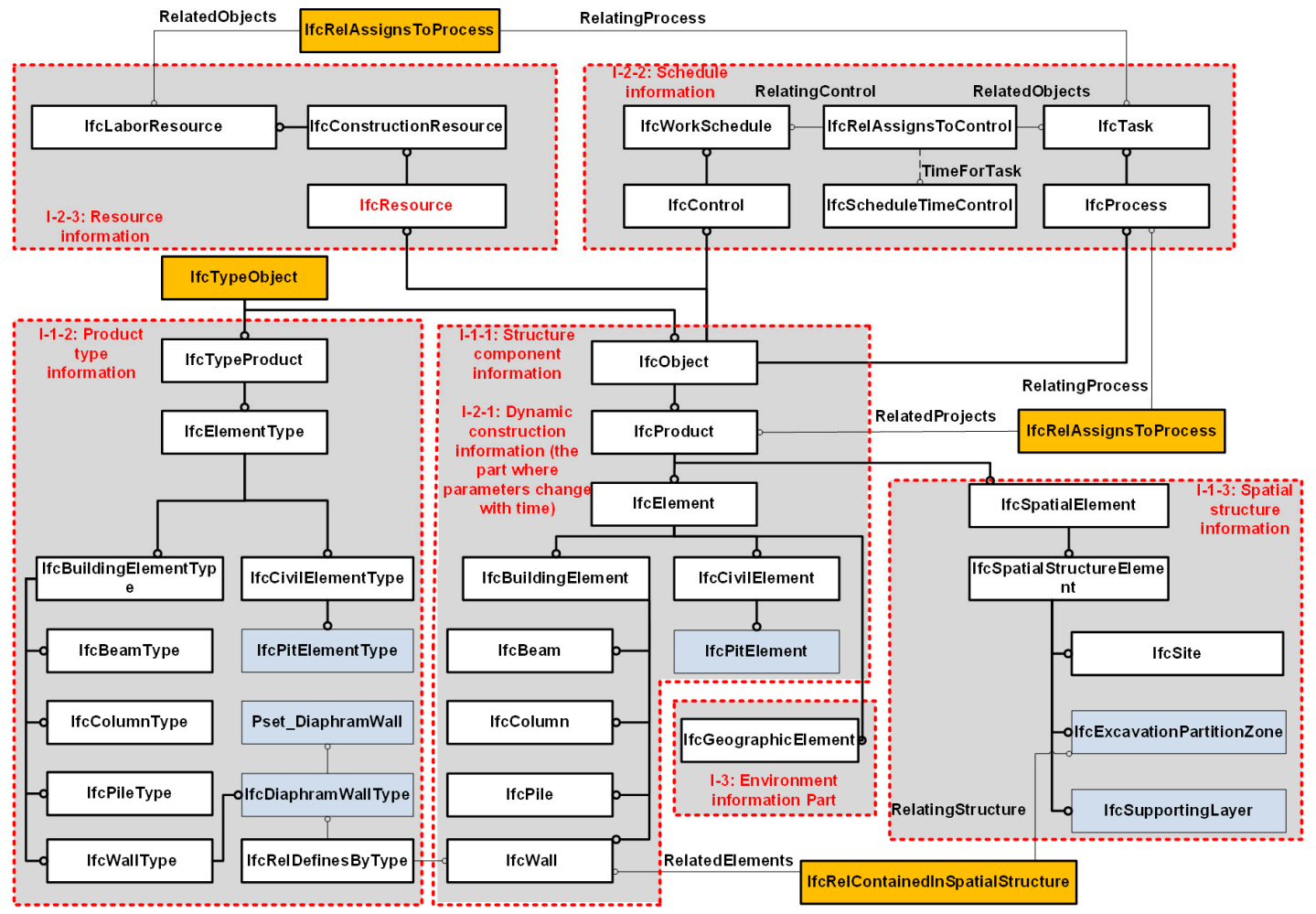

Figure 11. Framework of the IFC data model for safety risk identification of deep excavation projects.

\section{Application and Evaluation of the IFC Data Model in the Automatic Safety Risk Identification of Deep Excavation}

5.1. Workflow of the Automatic Safety Risk Identification Focusing on the Entire Deep Excavation Process

An IFC data model-based approach is proposed in this research to realize automatic safety risk identification focusing on the entire deep excavation process, which can be divided into five steps.

1. After establishing a deep excavation information model meeting the level of details for risk identification (i.e., meeting the information requirements according to the IFC data model), a complete IFC file can be produced and input into the established risk identification system application based on IFC.

2. Users can select a certain construction phase for safety risk identification. Then, a list with construction information requirements that reflect the dynamic construction condition on site is correspondingly generated by the risk identification system application.

3. In accordance with the information requirement list, necessary dynamic construction parameters (which can be obtained from field sensors and monitoring databases) are input based on the real-time construction states.

4. Based on risk identification rules, the risk identification system application retrieves and extracts required construction parameters from the IFC file and information 
requirement list. Then, the exported engineering parameters are converted into extensible markup language for risk reasoning.

5. Thereafter, the risk identification system application outputs the results, which mainly consist of two parts (selected by users): (1) identified safety risk events, which have high possibilities of occurrence, and (2) similar risk cases.

With the above process, safety risks in deep excavation projects can be identified automatically, aiming at the entire deep excavation process. Risk identification in the preconstruction stage is unrelated to the dynamic construction condition, which can be automatically conducted by the risk identification platform based on the IFC data model without dynamic information input.

\subsection{Prototype System for Safety Risk Identification Based on the IFC Data Model}

The safety risk identification of deep excavation according to the workflow above is realized by establishing a CRIS prototype based on the IFC data model [28]. The CRIS mainly contains three function modules: knowledge base management, information retrieval, and risk identification.

1. Knowledge base management module

The core function of this function module is to act as a risk identification knowledge base. Its main functions include fact, rule, and case base management. They are designed mainly to collect, store, and represent safety risk identification knowledge (e.g., risk knowledge facts, risk identification rules, and construction risk cases). Risk knowledge facts are the knowledge base for conducting risk identification. According to our previous work [36], eight essential parts of risk knowledge are involved in the fact base. Risk knowledge, such as 'safety risk', 'risk factor', and 'construction parameter', which are closely related to the risk reasoning and identification results, are mainly managed based on the information requirement model. Table 4 shows related risk knowledge aiming at the risk of 'surrounding structure cracking', which is described as an example.

Table 4. Main risk knowledge parts in the fact base

\begin{tabular}{cc}
\hline Risk Knowledge Part & Description \\
\hline 1. Construction method & The construction methods adopted in deep excavation projects \\
2. Supporting system & The supporting system adopted in deep excavation projects \\
3. Safety risk & Potential safety risks of certain construction methods using different supporting systems \\
4. Risk factor & Risk factors leading to potential safety risks \\
5. Construction parameters & Construction parameters leading to risk factors \\
6. Risk grade & Severity of a risk \\
7. Risk consequence & Expression of the outcomes of a risk \\
8. Risk prevention measurement & Expression of prevention measurements to certain risks \\
\hline
\end{tabular}

\section{Information retrieval module}

Based on the IFC data model, the information retrieval module retrieves and extracts construction parameters required for safety risk identification from IFC files [21]. Its main functions include information depth management, IFC retrieval, and construction information management.

\section{Risk reasoning module}

The risk reasoning module reasons safety risks involved in the construction process. It is operated in conjunction with the rule-based reasoning method, and its main functions include reasoning algorithm management, reasoning, and reasoning result output. The risk reasoning rules are stored in the rule base of the CRIS. The reasoning method for identifying potential safety risks is briefly illustrated as follows:

$$
\mathrm{CF}(e)=\sum_{i=1}^{n} \omega_{i} \times \mathrm{CF}\left(e_{i}\right) .
$$




$$
\mathrm{CF}(h)=\mathrm{CF}(\mathrm{h}, \mathrm{e}) \times \mathrm{CF}(e), \text { when, } \mathrm{CF}(e) \geq \lambda
$$

where $\mathrm{CF}\left(e_{i}\right)$ represents the certainty factor of certain value of a rule premise, $\omega_{i}$ is the weight factor of a rule premise to a certain risk, $\mathrm{CF}(e)$ is the certainty factor of rule premises of a certain risk, $\lambda$ is the threshold of the rule, $\mathrm{CF}(h, e)$ is the rule certainty factor, and $\mathrm{CF}(h)$ is the conclusion certainty factor.

\subsection{Safety Risk Identification Using the CRIS Prototype}

The effectiveness of the IFC data model-based safety risk identification approach is evaluated by conducting a case study in the background of a typical deep excavation project, using the CRIS prototype. It is a commercial building construction engineering in Zhengzhou, China, with an 18-storey upper structure and a 2-storey substructure. The excavation depth of this building project measures up to $10.5 \mathrm{~m}$. Soil nailing walls and pile anchors are utilized as a combined bracing system, and a light-well-point system is adopted as the dewatering method. When the opencut method is adopted, the deep excavation process can be divided into six phases: (1) preconstruction, (2) retaining structure establishment, (3) foundation treatment and dewatering, (4) foundation pit excavation, (5) main structure construction, and (6) foundation pit backfill. In this case study, safety risk identification in the foundation pit excavation phase is emphasized. The workflow of the safety risk identification process using the CRIS prototype is shown in Figure 12.

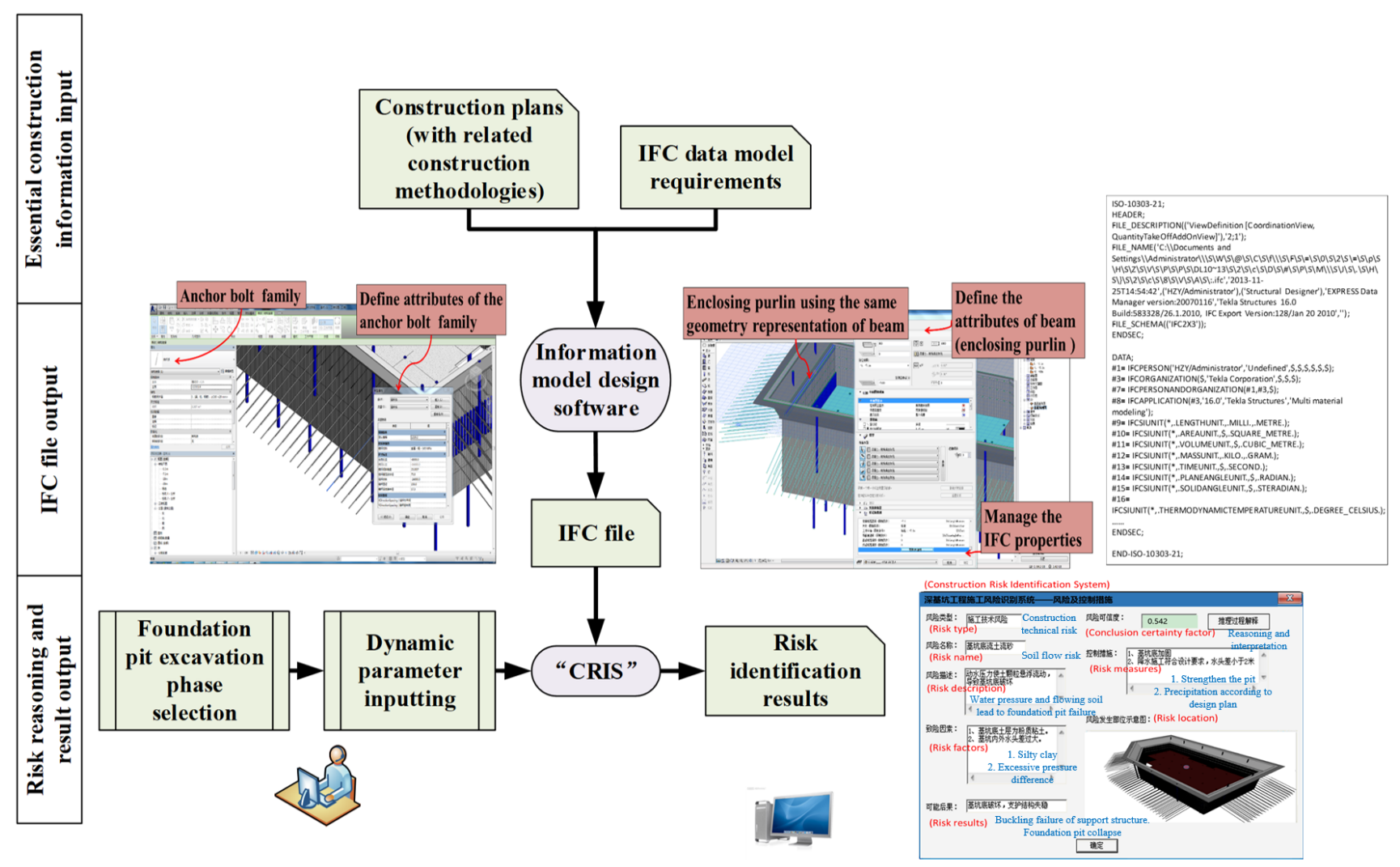

Figure 12. Workflow of the safety risk identification using CRIS. 
- IFC file generation

Based on the input construction plan and the IFC data model, a basic deep excavation information model was established in Revit ${ }^{\mathrm{TM}}$. The primary structure components, such as retaining piles and enclosing purlins, were expressed by entity objects defined in IFC4. For the subordinate components-such as soil nails, anchor bolts, and dewatering wells-their relevant component families with specific attributes were created. Then, these component families were added to the project file to express the corresponding subordinate components. The correctness and completeness of the required information defined above were identified, and the necessary custom property sets were introduced into the model by deriving the IFC file from Revit ${ }^{\mathrm{TM}}$ and importing it into ArchiCAD ${ }^{\mathrm{TM}}$. Then, necessary custom property sets were added to corresponding primary structural components to output a complete IFC file based on the IFC data model. When the IFC file was input into the CRIS prototype, a new project record was created.

- Risk identification and result output

After choosing the foundation pit excavation phase, a potential safety risk list was created in accordance with the construction methods adopted in this project. The information involved in the list contained potential safety risk events, related factors, and required construction parameters. Based on the potential safety risk list, the required construction parameters were extracted from the IFC files. Moreover, relevant construction parameters were input by users according to the dynamic construction sites and information requirement list output by the CRIS prototype. Then, the system initiated the safety risk reasoning and identification process. Figure 13 takes soil flow in the bottom of the foundation pit as an example to illustrate the output results.

(Construction Risk Identification System)

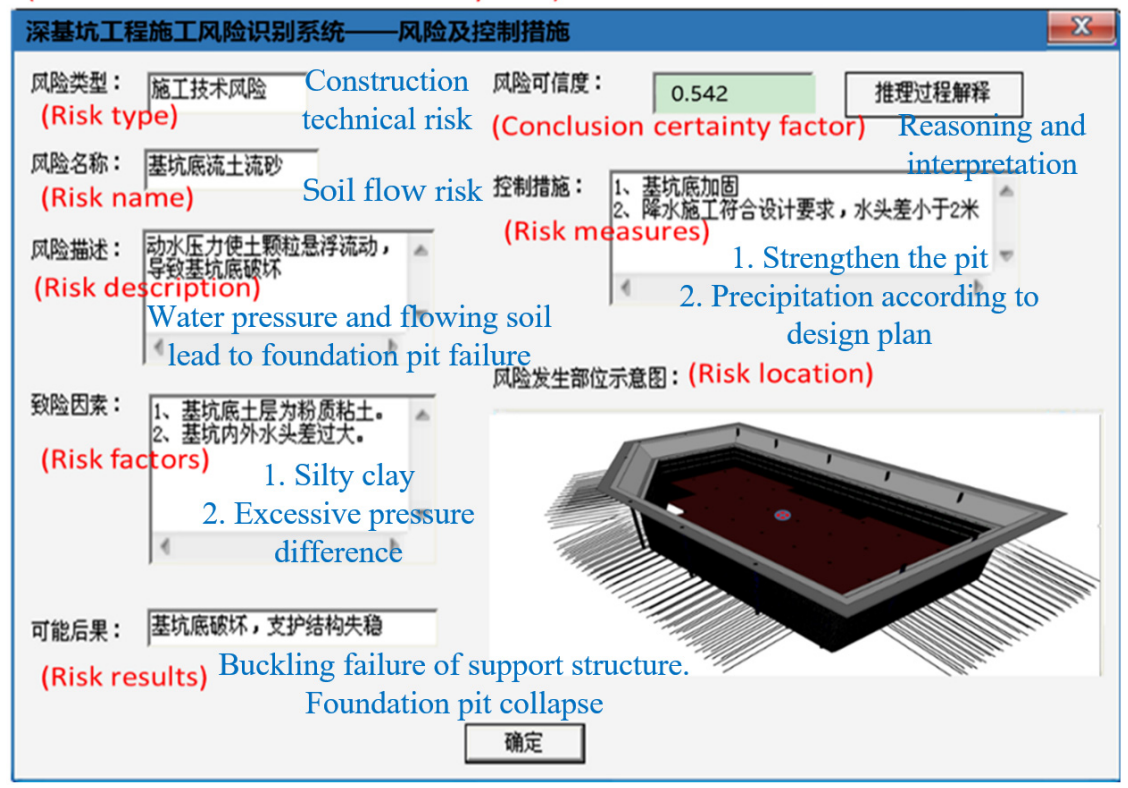

Figure 13. Safety risk identification results from the CRIS prototype (safety risk of soil flow in the bottom of the foundation pit). 


\subsection{Evaluation of the IFC-Based Safety Risk Identification}

The effectiveness of the results generated from the CRIS prototype was evaluated by performing a manual safety risk identification seminar. Two experts and three engineering practitioners with rich domain experiences from the Center for Virtual, Safe, and Automated Construction of Hubei Province were invited to identify the potential safety risks in this project. Considering the construction information in the foundation pit excavation phase, the participants conducted safety risk identification based on construction drawings, construction plans, risk management guidelines, and other documentation. After a two-hour evaluation and discussion, the identification results-and associated suggestions, which are shown in Table 5-were given by the seminar.

Table 5. Manual safety risk identification results and associated suggestions (partial)

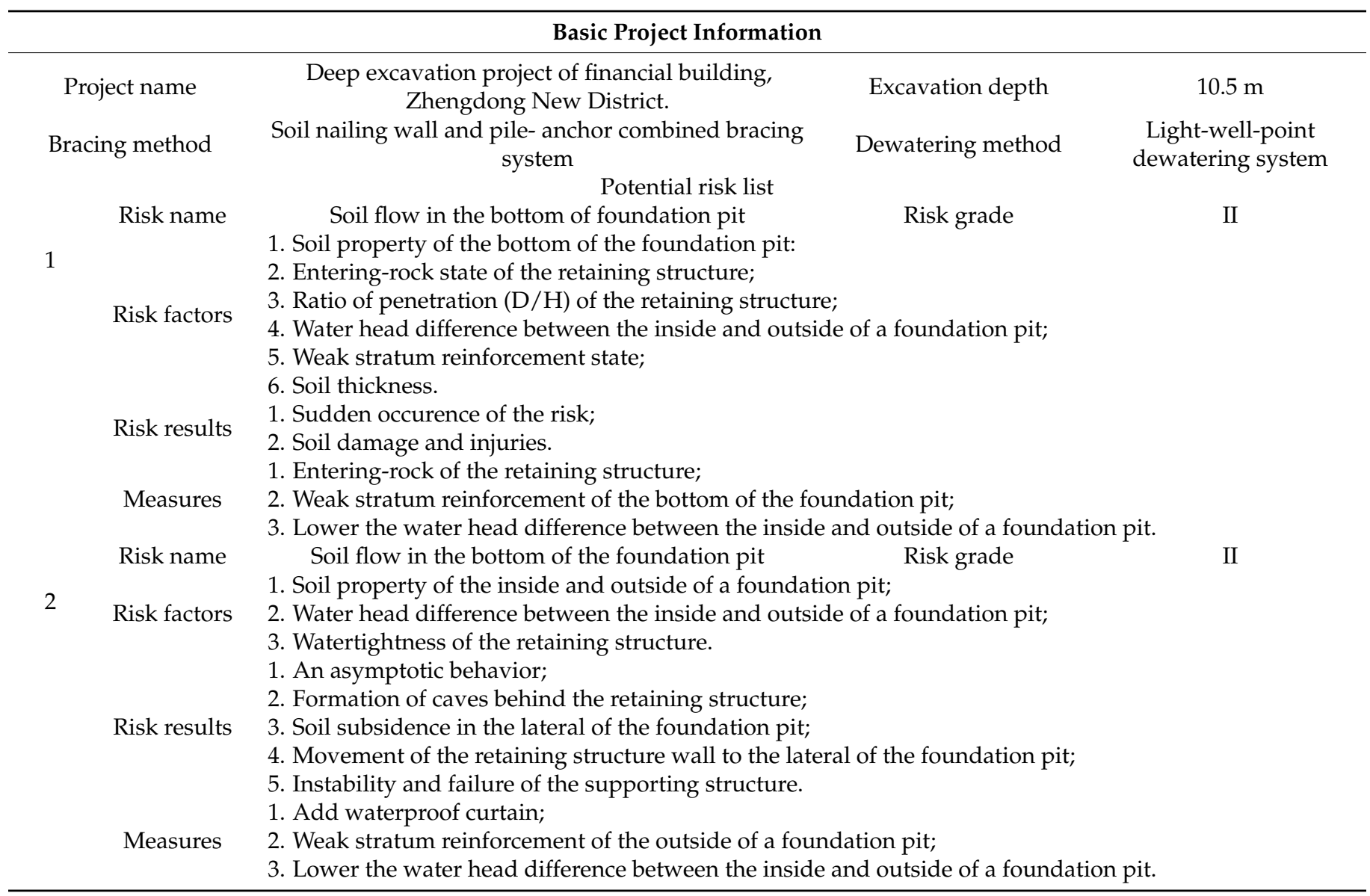

A comparison of the risk identification processes of the CRIS prototype and the seminar is shown in Table 6. Considering the main shortcomings of the traditional risk identification method (e.g., time and manpower consuming, comprehensiveness of identified risks, and subjectivity in risk-related information expression) and engineering practice, the effectiveness of the CRIS prototype is demonstrated from the following aspects: (1) the time- and manpower-saving process; (2) the accurate result by identifying more potential safety risks; and (3) the objective assessment with more related risk information. 
Table 6. Comparison of the safety risk identification process between the CRIS prototype and the seminar

\begin{tabular}{|c|c|c|}
\hline Comparing Points & Manual Risk Identification & Risk Identification Based on CRIS \\
\hline 1. Consumption of time & Two hours & Ten minutes \\
\hline $\begin{array}{l}\text { 2. Consumption of } \\
\text { manpower }\end{array}$ & Five domain experts & One user (any community) \\
\hline 3. Identified risk types & $\begin{array}{l}\text { Five types } \\
\text { Notes: } \\
\text { 1. The result list was determined through } \\
\text { expert discussion. } \\
\text { 2. Contained subjective factors } \\
\text { 3. Risks with greater probabilities were } \\
\text { identified. }\end{array}$ & 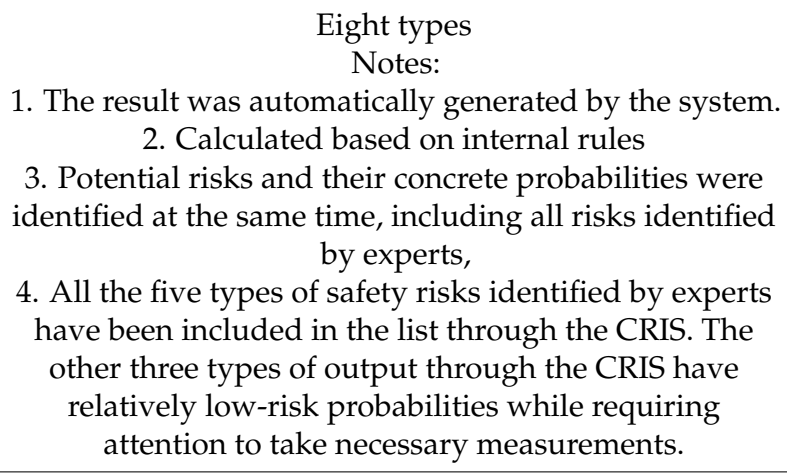 \\
\hline $\begin{array}{l}\text { 4. Risk information } \\
\text { expression form }\end{array}$ & $\begin{array}{c}\text { Included contents } \\
\text { Risk name, risk grade, risk factors, risk } \\
\text { result measures } \\
\text { Notes: } \\
\text { 1. Based on experts' knowledge and } \\
\text { experiments } \\
\text { 2. Contained subjective factors } \\
\text { 3. Not systematic }\end{array}$ & $\begin{array}{c}\text { Included contents } \\
\text { Risk type, risk name, risk reliability, risk factors, risk } \\
\text { results, measures, risk site expression } \\
\text { Notes: } \\
\text { 1. Based on the internal knowledge base } \\
\text { 2. Will not change along with the subjective factor } \\
\text { 3. Knowledge systematization }\end{array}$ \\
\hline
\end{tabular}

\section{Conclusions}

This research presents the development of a BIM-based central database, which aims to enable information integration and exchange between the dynamic deep excavation process and construction information in project planning documentation to support automatic safety risk identification. In this process, the required construction information elements and involved relationships (i.e., logical relationships and constraints among risk events, risk factors, construction parameters, and construction phases) arising during the dynamic construction process are examined and integrated. The IFC definition used in this research acts as an important role in the central database establishment by meeting the information expression requirements. An automatic risk identification approach is proposed based on the IFC data model. Accordingly, a CRIS prototype is developed and tested under the BIM environment. The effectiveness of the BIM-based central database in accelerating automatic safety risk identification is illustrated by linking BIM elements and required construction information corresponding to the dynamic construction process. Furthermore, the IFC standard presented in this research can be used as the data storage standard for field sensors and monitoring databases in future applications. Moreover, BIM-based visualization can be supported through the IFC-based risk identification assisting platform, and the research output can be utilized to facilitate decision-making for the promotion of safety risk management in deep excavation.

\subsection{Innovation}

Comparing with the research documents of safety management based on BIM [37-39], it is the first time focusing on the information integration and exchange for the safety risk identification of deep excavation construction based on IFC in this research work. This research presents an approach of automatic construction risk identification aiming at the entire deep excavation process, based on the extended IFC model. A system prototype for risk identification is established and a practical deep excavation project is taken as the testing background. Results illustrate the effectiveness of the IFC data model in accelerating automatic safety risk identification by supporting the information integration and exchange 
between the dynamic deep excavation process and the established building information models. Decision making for taking timely risk control measures can be assisted, which then promotes safety risk management in deep excavation projects.

\subsection{Limitations and Future Work}

There are some limitations to be addressed in future research in this area. Safety risks of deep excavation projects vary (i.e., technical, geological, environment, equipment, behavioral, and management). This research mainly focused on the first three types. The proposed IFC data model can be expanded in the future to cover more risk types and accelerate the application of related assisting platforms in extended fields. Additionally, for typical risk (e.g., geological risks), comprehensive risk factors (including soils composition heterogeneity and surveying uncertainty) and corresponding risk identification rules should be identified. Risk identification application with more practical project cases should be conducted to evaluate and improve the IFC data model and the IFC-based risk identification approach. In addition to the adoption of the IFC data model, risk identification-related assisting platforms should also optimize reasoning algorithms and function implementations further to enable the most valid application in the future.

Author Contributions: Conceptualization, Y.Z.; Data curation, X.X.; Funding acquisition, Y.Z.; Investigation, M.F.A.-A.; Methodology, Y.Z.; Visualization, X.X.; Writing—original draft, Y.Z.; Writingreview and editing, X.X. and M.F.A.-A. All authors have read and agreed to the published version of the manuscript.

Funding: This research was funded by the National Natural Science Foundation of China, grant number 71901104; Jiangsu Department of Housing and Construction project, grant number 2019ZD001085; Jiangsu Academy of Productivity Science project, grant number JSSCL2020A010; and Jiangsu Smart Factory Engineering Research Center project, grant number JSSFER2019A3.

Institutional Review Board Statement: Not applicable.

Informed Consent Statement: Not applicable.

Data Availability Statement: All data related to this study is explicitly plotted in the figures in this article.

Conflicts of Interest: The authors declare no conflict of interest. The funders had no role in the design of the study; in the collection, analyses, or interpretation of data; in the writing of the manuscript, or in the decision to publish the results.

\section{References}

1. Ding, L.Y.; Xu, J. A review of metro construction in China: Organization, market, cost, safety and schedule. Front. Eng. Manag. 2017, 4, 4-19. [CrossRef]

2. Zhang, Y.; Ding, L.; Love, P.E. Planning of deep foundation construction technical specifications using improved case-based reasoning with weighted k-nearest neighbors. J. Comput. Civil. Eng. 2017, 31, 04017029. [CrossRef]

3. Nie, T.; Xing, H. Risk control analysis of metro construction based on complex system brittleness theory. Electron. J. Geotech. Eng. 2016, 21, 9797-9806.

4. Zhang, S.; Teizer, J.; Lee, J.K.; Eastman, C.M.; Venugopal, M. Building information modeling (BIM) and safety: Automatic safety checking of construction models and schedules. Autom. Constr. 2013, 29, 183-195. [CrossRef]

5. Ding, L.Y.; Zhong, B.T.; Wu, S.; Luo, H.B. Construction risk knowledge management in BIM using ontology and semantic web technology. Saf. Sci. 2016, 87, 202-213. [CrossRef]

6. Meng, L.; Yu, H.; Jin, H.; Ping, L. Methodologies of safety risk control for China's metro construction based on BIM. Saf. Sci. 2018, $110,418-426$.

7. Zhou, Y.; Ding, L.Y.; Chen, L.J. Application of 4D visualization technology for safety management in metro construction. Autom. Constr. 2012, 34, 25-36. [CrossRef]

8. Zhang, S.; Boukamp, F.; Teizer, J. Ontology-based semantic modeling of construction safety knowledge: Towards automated safety planning for job hazard analysis (JHA). Autom. Constr. 2015, 52, 29-41. [CrossRef]

9. Zhang, L.; Wu, X.; Ding, L.; Skibniewski, M.J.; Lu, Y. Bim-based risk identification system in tunnel construction. J. Civ. Eng. Manag. 2016, 22, 529-539. [CrossRef]

10. Ding, L.; Li, K.; Zhou, Y.; Love, P.E. An IFC-inspection process model for infrastructure projects: Enabling real-time quality monitoring and control. Autom. Constr. 2017, 84, 96-110. [CrossRef] 
11. Xu, Z.; Huang, T.; Li, B.; Li, H.; Li, Q. Developing an IFC-based database for construction quality evaluation. Adv. Civ. Eng. 2018, 2018, 3946051. [CrossRef]

12. Dhillon, R.K.; Jethwa, M.; Rai, H.S. Extracting building data from BIM with IFC. Int. J. Recent Trends Eng. Technol. 2014, 11, 202-211.

13. Park, S.I.; Park, J.; Kim, B.-G.; Lee, S.-H. Improving applicability for information model of an IFC-based steel bridge in the design phase using functional meanings of bridge components. Appl. Sci. 2018, 8, 2531. [CrossRef]

14. Kiviniemi, M.; Sulankivi, K.; Kähkönen, K.; Mäkelä, T.; Merivirta, M.L. BIM-based safety management and communication for building construction. VTT Tied. Valt. Tek. Tutk. 2011, 22, 1-123.

15. Hou, L.; Chen, H.; Zhang, G.; Wang, X. Deep learning-based applications for safety management in the AEC industry: A review. Appl. Sci. 2021, 11, 821. [CrossRef]

16. Jeffrey, W. IFC 2x EXTENSIONMODELLING Guide. 2010. Available online: http://www.iaichina.org/Model/documentation/ Ifc2x---EMG/EMG---Base.htm (accessed on 26 September 2016).

17. Wang, Y.; Zhang, J. BIM-based design of structural working drawing. J. South China Univ. Technol. 2013, 41, 76-82.

18. Ji, Y.; Borrmann, A.; Beetz, J.; Obergrießer, M. Exchange of parametric bridge models using a neutral data format. J. Comput. Civ. Eng. 2013, 27, 593-606. [CrossRef]

19. Lee, S.H.; Sang, I.P.; Park, J. Development of an IFC-based data schema for the design information representation of the NATM tunnel. KSCE J. Civ. Eng. 2015, 20, 2112-2123. [CrossRef]

20. Zhou, Y.; Wang, Y.; Ding, L.; Love, P.E. Utilizing IFC for shield segment assembly in underground tunneling. Autom. Constr. 2018, 93, 178-191. [CrossRef]

21. Kim, H.; Kim, J. A case-based reasoning model for retrieving window replacement costs through industry foundation class. Appl. Sci. 2019, 9, 4728. [CrossRef]

22. Yang, B.; Dong, M.; Wang, C.; Liu, B.; Wang, Z.; Zhang, B. IFC-based 4D construction management information model of prefabricated buildings and its application in graph database. Appl. Sci. 2021, 11, 7270. [CrossRef]

23. Ma, Z.; Wei, Z.; Wu, S.; Zhe, L. Application and extension of the IFC standard in construction cost estimating for tendering in China. Autom. Constr. 2011, 20, 196-204.

24. Ma, Z.; Wei, Z.; Zhang, X. Semi-automatic and specification-compliant cost estimation for tendering of building projects based on IFC data of design model. Autom. Constr. 2013, 30, 126-135. [CrossRef]

25. Shi, J.; Dao, J.; Jiang, L.; Pan, Z. Research on IFC-and FDS-based information sharing for building fire safety analysis. Adv. Civ. Eng. 2019, 2019, 3604369. [CrossRef]

26. Kim, I.; Seo, J. Development of IFC modeling extension for supporting drawing information exchange in the model-based construction environment. J. Comput. Civ. Eng. 2008, 22, 159-169. [CrossRef]

27. Fang, W.; Ding, L.; Luo, H.; Love, P.E. Falls from heights: A computer vision-based approach for safety harness detection. Autom. Constr. 2018, 91, 53-61. [CrossRef]

28. Ding, L.Y.; Yu, H.L.; Li, H.; Zhou, C.; Wu, X.G.; Yu, M.H. Safety risk identification system for metro construction on the basis of construction drawings. Autom. Constr. 2012, 27, 120-137. [CrossRef]

29. Luo, H.B.; Gong, P.S. A BIM-based code compliance checking process of deep foundation construction plans. J. Intell. Roboti. Syst. 2015, 79, 549-576. [CrossRef]

30. Zhang, Y. Research on BIM-Based Construction Domain Text Information Management; Tsinghua University: Beijing, China, 2009.

31. BuildingSMART. Industry Foundation Classes Release 4 (IFC4). 2013. Available online: http://www.buildingsmart-tech.org/ifc/ IFC4/ final/html/ (accessed on 13 September 2016).

32. Adeli, H.; Karim, A. Construction Scheduling, Cost Optimization, and Management-A New Model Based on Neurocomputing and Object Technologies; Spon Press: London, UK, 2001.

33. $\mathrm{Hu}, \mathrm{Z}$; Z Zhang, J. BIM-and 4D-based integrated solution of analysis and management for conflicts and structural safety problems during construction: 2. development and site trials. Autom. Constr. 2011, 20, 167-180. [CrossRef]

34. Tanyer, A.M.; Aouad, G. Moving beyond the fourth dimension with an IFC-based single project database. Autom. Constr. 2005, 14, 15-32. [CrossRef]

35. Noardo, F.; Arroyo Ohori, K.; Krijnen, T.; Stoter, J. An inspection of IFC models from practice. Appl. Sci. 2021, 11, 2232. [CrossRef]

36. Zhong, B.; Li, Y. An ontological and semantic approach for the construction risk inferring and application. J. Intell. Roboti. Syst. 2015, 79, 449-463. [CrossRef]

37. Tian, W.; Meng, J.; Zhong, X.; Tan, X. Intelligent early warning system for construction safety of excavations adjacent to existing metro tunnels. Adv. Civ. Eng. 2021, 2021, 8833473.

38. Wenpeng, D.; Maoxuan, Q.; Xiaofeng, F.; Yixuan, W. Safety monitoring platform for deep excavation based on BIM and big data technology. In Proceedings of the 2020 International Conference on Robots \& Intelligent System (ICRIS), Sanya, China, 7-8 November 2020; IEEE: Piscataway, NJ, USA, 2020.

39. Wu, I.; Lu, S.; Hsiung, B. A BIM-based monitoring system for urban deep excavation projects. Vis. Eng. 2015, 3, 2. [CrossRef] 